\title{
29 THE PRESENT SITUATION AND TRENDS OF WASTEWATER TREATMENT IN SMALL SETTLEMENTS AND RURAL AREAS OF LITHUANIA
}

\author{
Regimantas Dauknys \\ Vilnius Gediminas Technical University, Lithuania
}

\begin{abstract}
This article presents the wastewater treatment in small settlements and rural areas of Lithuania, including descriptions of capacity and loading of wastewater treatment plants (WWTPs), types of treatment facilities, and development trends of biological treatment facilities. In 2000 Lithuania had 597 WWTPs with capacity up to $1000 \mathrm{~m}^{3} / \mathrm{d}, 95 \%$ of them are the biological treatment plants. Today the most of these WWTPs are unloaded due to the tendency to centralise wastewater treatment in rural areas of Lithuania that were in the eight and ninth decades.

In small settlements and rural areas of Lithuania the aeration facilities are predominant. In the eight and ninth decades practically only the activated sludge systems were built. The situation began to change in the last decade of the last century: the biological filters and soil filtration facilities with discharge into surface waters were applied more frequently, so the building of aeration facilities started to decrease.
\end{abstract}

\section{KEYWORDS}

Wastewater treatment, small settlements, rural areas, wastewater treatment plants, biological treatment.

\section{INTRODUCTION}

The Republic of Lithuania is a small country with an area of about $65000 \mathrm{~km}^{2}$ and a population of 3.7 million. Less than half of the population lives in small settlements and rural areas.

Wastewater collection and treament on a great part predetermines the state of surface and underground water resources in the general structure of region water management. It has also an influence on matters related to the water quality: human health, recreation conditions, peculiarity of landscape, streams of tourism, biodiversity, etc.

In the eight and ninth decades it was the tendency to centralise wastewater treatment in the rural areas of Lithuania, i. e. to connect living, public, industrial and agricultural objects into the common sewerage system and to treat wastewater in the municipal wastewater treatment plants (WWTPs). Therefore, in rural areas the most part of WWTPs was built with an excess capacity (for perspective). 
Due to the lack of pipes, building materials and other possibilities a great part of the objects was not connected into the sewerage and WWTPs became unloaded or they were not exploited at all.

The Lithuanian experience showed that the centralised (municipal) sewerage and wastewater treatment systems in rural areas have the following disadvantages:

- the quantity of sewage is small but the distances are large. So, the length of pipeline and also construction and maintenance costs for one inhabitant are relatively high;

- the sewerage often plugs due to the great fluctuations of flow rate and the decrease of velocity in the night;

- in most cases the pump stations are required;

- it is difficult to maintenance the complex wastewater treatment facilities due to the lack of skilled personal;

- when wastewater treatment facilities are maintained improperly and optimal loading for these facilities is not created, not only the cost for electricity rises but also the required degree of treatment is not achieved.

The aim of this article is to overview the state of WWTPs in small settlements and rural areas of Lithuania and to reveal the development trends of wastewater treatment.

\section{DEVELOPMENT OF WASTEWATER TREATMENT IN SMALL SETTLEMENTS AND RURAL AREAS}

\section{State of wastewater treatment plants during 1995-1998}

In the beginning of 1998 Lithuanian cities and settlements had 787 WWTPs with discharge into surface waters and filtration fields. 657 (or 83.5\%) of these wastewater treatment plants were located in rural areas. The non-operating treatment facilities in such areas comprised $16.7 \%$, and then this percent was almost 2 times higher in $1995(31 \%)(1)$. According to the data of 1998 a half of the treatment facilities did not operate due to the lack of loading, the other part of facilities did not operate due to required repair, re-construction or absence of required equipment (Figure 1).

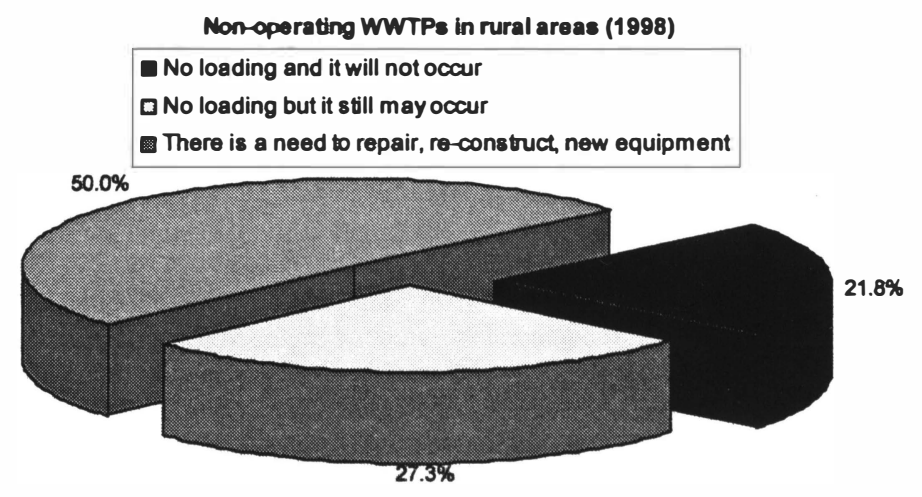

Figure 1. Distribution of non-operating WWTPs in rural areas of Lithuania according to the reason (data of 1998) 
Table 1. Information on changes managing the wastewater treatment plants in rural areas of Lithuania during 1995-1998 (1)

\begin{tabular}{|c|c|c|c|c|c|c|}
\hline Year & Written off & $\begin{array}{c}\text { Temporarily } \\
\text { closed }\end{array}$ & $\begin{array}{c}\text { Re- } \\
\text { constructed }\end{array}$ & New & $\begin{array}{c}\text { Under re- } \\
\text { construction }\end{array}$ & $\begin{array}{c}\text { Projects (prepared or } \\
\text { under preparation) }\end{array}$ \\
\hline 1995 & 22 & 19 & $\mathbf{8}$ & - & - & - \\
\hline 1996 & 44 & 24 & 30 & 24 & - & - \\
\hline 1997 & $\mathbf{8}$ & 26 & 7 & 12 & - & - \\
\hline 1998 & 3 & 9 & 29 & 10 & 12 & 40 \\
\hline $\mathbf{1 9 9 5 - 1 9 9 8}$ & $\mathbf{7 7}$ & $\mathbf{7 8}$ & $\mathbf{7 4}$ & $\mathbf{4 6}$ & $\mathbf{1 2}$ & $\mathbf{4 0}$ \\
\hline
\end{tabular}

74 WWTPs were reconstructed, 46 WWTPs were built and 77 non-operating WWTPs were written off in the period of 1995-1998 (Table 1). This explains the increase of operating WWTPs in rural areas of Lithuania.

\section{Capacity and loading of WWTPs}

The information on discharge of wastewater and operation of wastewater treatment plants is collected in the Joint Research Centre of the Ministry of Environment of Lithuania. Therefore, for this study data were taken from the Joint Research Centre (2).

In order to characterise the wastewater treatment facilities in small settlements and rural areas of Lithuania in 2000 , the WWTPs with capacity up to $1000 \mathrm{~m}^{3} / \mathrm{d}$ were analysed.

When the treatment facilities of more than $1000 \mathrm{~m}^{3} / \mathrm{d}$ capacity were rejected, it is obtained that in 2000 Lithuania had 597 WWTPs with capacity up to $1000 \mathrm{~m}^{3} / \mathrm{d}$. 549 of them had discharge into surface waters and 48 of them were filtration fields including agricultural irrigation fields.

These 597 WWTPs were grouped according to the capacity. Five groups were chosen. The obtained results are given in Table 2.

Table 2. The distribution of wastewater treatment plants according to the capacity

\begin{tabular}{|c|c|c|c|}
\hline $\begin{array}{c}\text { Capacity of WWTPs, } \\
\mathrm{m}^{3} / \mathrm{d}\end{array}$ & $\begin{array}{c}\text { Number of WWTPs, } \\
\text { unit }\end{array}$ & $\begin{array}{c}\text { Population equivalent } \\
\text { (PE) }\end{array}$ & $\begin{array}{c}\% \text { of total number of } \\
\text { WWTPs }\end{array}$ \\
\hline up to 50 & 155 & up to 200 & 26 \\
\hline $51-100$ & 156 & $200-400$ & 26 \\
\hline $101-250$ & 167 & $400-1000$ & 28 \\
\hline $251-500$ & 77 & $1000-2000$ & 13 \\
\hline $501-1000$ & 42 & $2000-4000$ & 7 \\
\hline
\end{tabular}

The WWTPs with capacity up to $250 \mathrm{~m}^{3} / \mathrm{d}$ are predominated. Such treatment facilities comprise $80 \%$ of total number of analysed WWTPs. The facilities with capacities of $251-$ $500 \mathrm{~m}^{3} / \mathrm{d}$ comprise $13 \%$ and the facilities with capacities of $501-1000 \mathrm{~m}^{3} / \mathrm{d}$ comprise $7 \%$ of total number of the WWTPs.

Total capacity and loading of treatment facilities with discharge into surface waters were compared. The results are summarised in Figure 2.

The total capacity of WWTPs that have the biological treatment step very differed from the total loading. In 2000 the employment of these facilities was $26 \%$. The total employment was $29 \%$. Such situation formed due to the tendency to centralise wastewater treatment in rural areas of Lithuania that were in the eight and ninth decades. 
WWTPs with discharge into surface waters (2000)

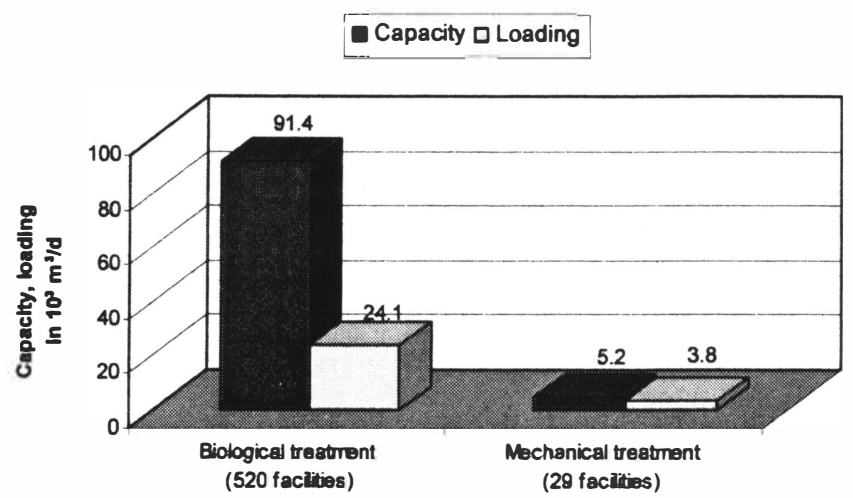

Figure 2. Distribution of total capacities and loading of WWTPs with capacity up to $1000 \mathrm{~m}^{3} / \mathrm{d}$ (data of 2000)

Today the most of WWTPs with capacity up to $1000 \mathrm{~ms}^{3} / \mathrm{d}$ are unloaded, so their effective operation usually cannot be ensured. According to the obtained results the biological treatment facilities that are applied in small settlements and rural areas of Lithuania should be orientated to the capacity up to $150 \mathrm{~ms}^{3} / \mathrm{d}$.

\section{Types of WWTPs}

Trying to determine the distribution of types of wastewater treatment facilities and their distribution in respect of the year of construction, the WWTPs with capacity up to $1000 \mathrm{~ms} / \mathrm{d}$ (597 WWTPs) were grouped according to the proposed classification of treatment facilities for small settlements of Lithuania (Table 3). This classification is based on the following considerations:

- the wastewater treatment facilities are grouped according to the main step of wastewater treatment;

- the group of biological treatment facilities is subdivided into four subgroups according to the intensity of treatment process: a) activated sludge facilities, b) biological fixed film facilities, c) biological ponds, d) soil filtration facilities;

- the biological filters are grouped according to the conditions that are created for microorganisms, i. e. aerobic biofilters and anaerobic biofilters;

- taking into account that filtration is performed through the man-formed or natural soil, it is proposed the filtration facilities to call as soil filtration facilities and to subdivide them into two subgroups: a) soil filtration facilities with discharge into surface waters, and b) soil filtration facilities without discharge into surface waters;

- non-pure types or hybrid facilities are classified according to the predominant mode of treatment or they are attached to the group "other modes of biological treatment.

The distribution of WWTPs according to the type is shown in Figure 3. In Lithuania the biological treatment is the most commonly used wastewater treatment method. As the main treatment step it is applied in the $95 \%$ of the WWTPs with capacity up to $1000 \mathrm{~m}^{3} / \mathrm{d}$. The WWTPs with mechanical treatment comprise only $5 \%$. The physical-chemical treatment was not applied in small settlements and rural areas of Lithuania in 2000. 
KALMAR ECO-TECH'01

Leachate and Wastewater Treatment with High-Tech and Natural systems KALMAR, SWEDEN, November 26-28, 2001

Table 3. Proposed classification of treatment facilities for small settlements of Lithuania

\begin{tabular}{|c|c|c|c|}
\hline No. & \multicolumn{3}{|c|}{\begin{tabular}{|c|c|} 
Type of wastewater treatment facilities \\
\end{tabular}} \\
\hline 1. & \multicolumn{3}{|c|}{ Mechanical treatment facilities } \\
\hline & \multirow[t]{4}{*}{1.1} & \multicolumn{2}{|c|}{ Mechanical treatment facilities without digestion of sediments } \\
\hline & & \begin{tabular}{|l|l}
1.1 .1 \\
\end{tabular} & Vertical settling tanks \\
\hline & & 1.1 .2 & Horizontal settling tanks \\
\hline & & 1.1 .3 & Radial settling tanks \\
\hline & \multirow[t]{3}{*}{1.2} & \multicolumn{2}{|c|}{ Mechanical trearment facilities with digestion of sediments } \\
\hline & & 1.2 .1 & Two-floor settling tanks (Imhoff settling tanks) \\
\hline & & 1.2 .2 & Septic tanks \\
\hline \multirow[t]{3}{*}{2.} & \multicolumn{3}{|c|}{ Physical-chemical treatment facilities } \\
\hline & 2.1 & \multicolumn{2}{|c|}{ Flotation facilities } \\
\hline & 2.2 & \multicolumn{2}{|c|}{ Gravity facilities } \\
\hline \multirow[t]{7}{*}{3.} & \multicolumn{3}{|c|}{ Aeration facilities (activated sludge facilities) } \\
\hline & \multirow[t]{3}{*}{3.1} & \multicolumn{2}{|c|}{ Aeration-settling tanks } \\
\hline & & 3.1 .1 & Aeration-settling tanks with diffused aeration \\
\hline & & 3.1 .2 & Aeration-settling tanks with mechanical aeration \\
\hline & \multirow[t]{3}{*}{3.2} & \multicolumn{2}{|c|}{ Oxidation ditches } \\
\hline & & 3.2 .1 & Oxidation ditches with diffused aeration \\
\hline & & 3.2 .2 & Oxidation ditches with mechanical aeration \\
\hline \multirow[t]{3}{*}{4.} & \multicolumn{3}{|c|}{ Biological filters (biological fixed film facilities) } \\
\hline & 4.1 & \multicolumn{2}{|c|}{ Aerobic biological filters } \\
\hline & 4.2 & \multicolumn{2}{|c|}{ Anaerobic biological filters } \\
\hline \multirow[t]{3}{*}{5.} & \multicolumn{3}{|c|}{ Biological ponds } \\
\hline & 5.1 & \multicolumn{2}{|c|}{ Continuous flow biological ponds } \\
\hline & 5.2 & \multicolumn{2}{|c|}{ Plug flow biological ponds } \\
\hline \multirow[t]{7}{*}{6.} & \multicolumn{3}{|c|}{ Soil filtration facilities } \\
\hline & 6.1 & \multicolumn{2}{|c|}{ Soil filtration facilities with discharge into surface waters } \\
\hline & & 6.1 .1 & Sand-gravel filters \\
\hline & & 6.1 .2 & Soil-root filters \\
\hline & \multirow[t]{3}{*}{6.2} & \multicolumn{2}{|c|}{ Soil filtration facilities without discharge into surface waters } \\
\hline & & 6.2 .1 & Infiltration facilities (filtration fields, wells, trenches) \\
\hline & & 6.2 .2 & Agricultural irrigation fields \\
\hline 7. & Othe & modes & of biological treatment \\
\hline
\end{tabular}

\section{WWTPs with capacity up to $1000 \mathrm{~m}^{3} / \mathrm{d}$}

\begin{tabular}{|ll|}
\hline$\square$ Mechanical treatment facilities & Aeration facilities \\
$\square$ Biological filters & Biological ponds \\
$\square$ Soil filtration facilities & $\square$ Other modes of biological treatment
\end{tabular}

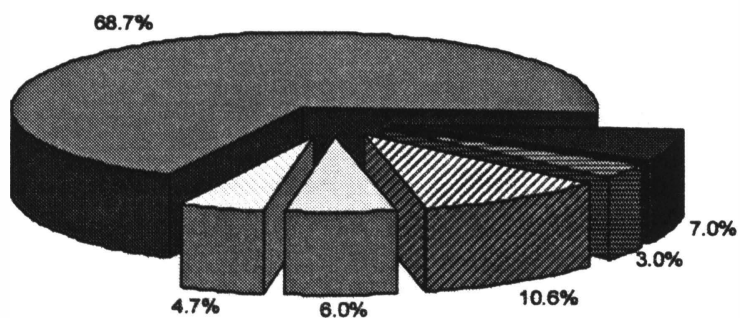

Figure 3. The distribution of WWTPs according to the type in 2000 
KALMAR ECO-TECH' 01

Leachate and Wastewater Treatment with High-Tech and Natural systems

KALMAR, SWEDEN, November 26-28, 2001

Aeration facilities

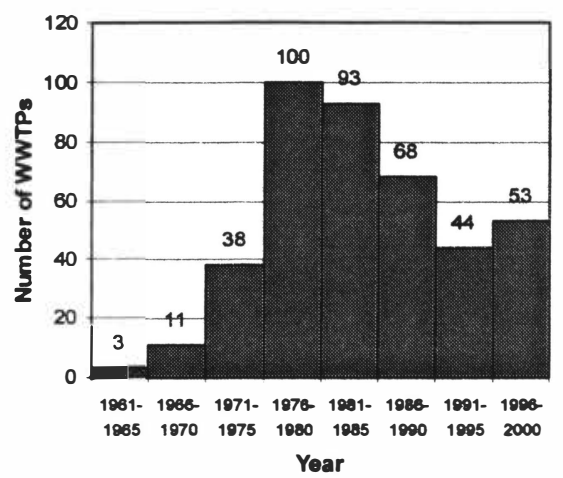

Biological filters

20

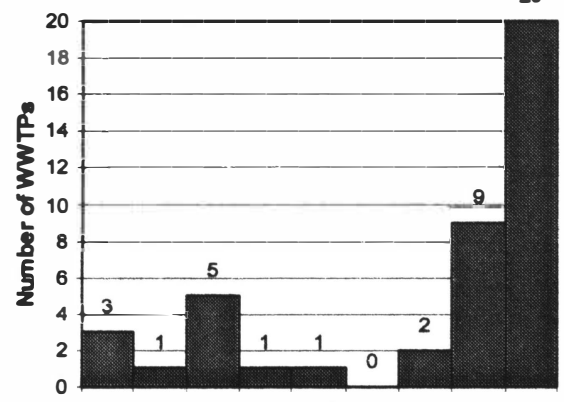

1955- 1961- 1968-1971- 1976-1981- 1986- 1991- 1906 $\begin{array}{lllllllll}1060 & 1985 & 1970 & 1975 & 1980 & 1985 & 1990 & 1995 & 2000\end{array}$

Biological ponds

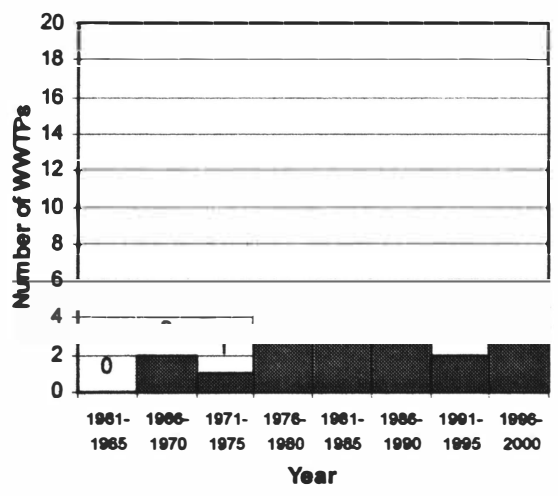

Soil filtration facllities without discharge into surface waters

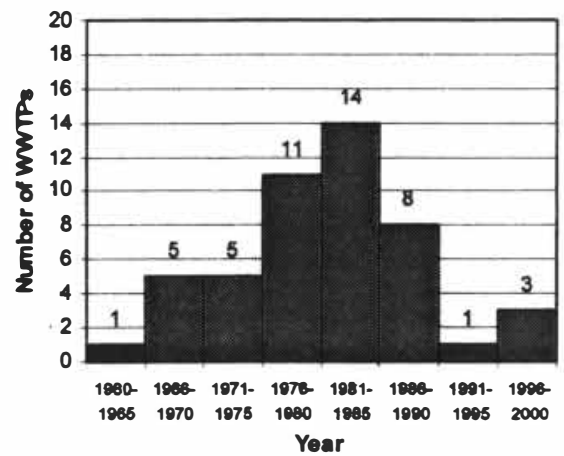

Soll filtration facilities with discharge into surface waters

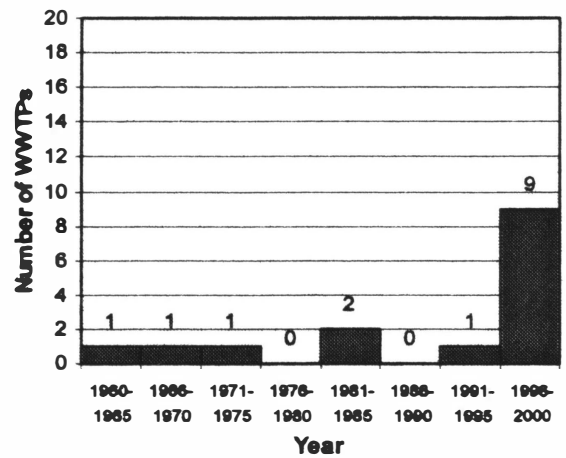

Figure 4. Development trends of different types of biological treatment facilities 
Reviewing the biological treatment in small settlements and rural areas of Lithuania it may be stated that the aeration facilities are predominant (68.7\% of analysed WWTPs). The soil filtration facilities take the second place according to the abundance. But they comprise $10.6 \%$ of total number of analysed WWTPs. The biofilters take the third place; their part is $7 \%$ only. In Lithuania the biological ponds are usually used as final treatment step. For the main step the biological ponds are used seldom, so their number is the smallest and comprises $3 \%$ of total number of the WWTPs.

\section{Biological treatment}

The development of different biological treatment facilities up to $1000 \mathrm{~ms}^{3} / \mathrm{d}$ is illustrated in Figure 4. In Lithuania all modes of biological treatment were valued more or less evenly up to the end of 1970. But in the eight and ninth decades practically only the activated sludge systems were built. The attention was so concentrated on the development of these technologies that the most specialists forgot the good points of other biological treatment methods. This fact stipulated the decrease of WWTPs in which the biological filters were used.

In the period of 1976-1990 several soil filtration facilities without discharge into surface waters were built. The most probably these facilities were built due to the absence of surface waters close to the objects or due to the favourable filtration conditions and possibility to use the required areas of land (for such facilities usually considerable areas of land are required). In the last decade of the last century the building of aeration facilities began slightly decrease. Such trend formed due to more frequent application of biological filters and soil filtration facilities with discharge into surface waters (Figure 4). The experience of foreign countries was also influenced the reviving of building of these treatment facilities. Lately the construction of aeration facilities decreased but the activated sludge systems still remain the main systems that are used for wastewater treatment in small settlements and rural areas.

The more detailed analysis of the construction of biofilters and soil filtration facilities with discharge were performed.
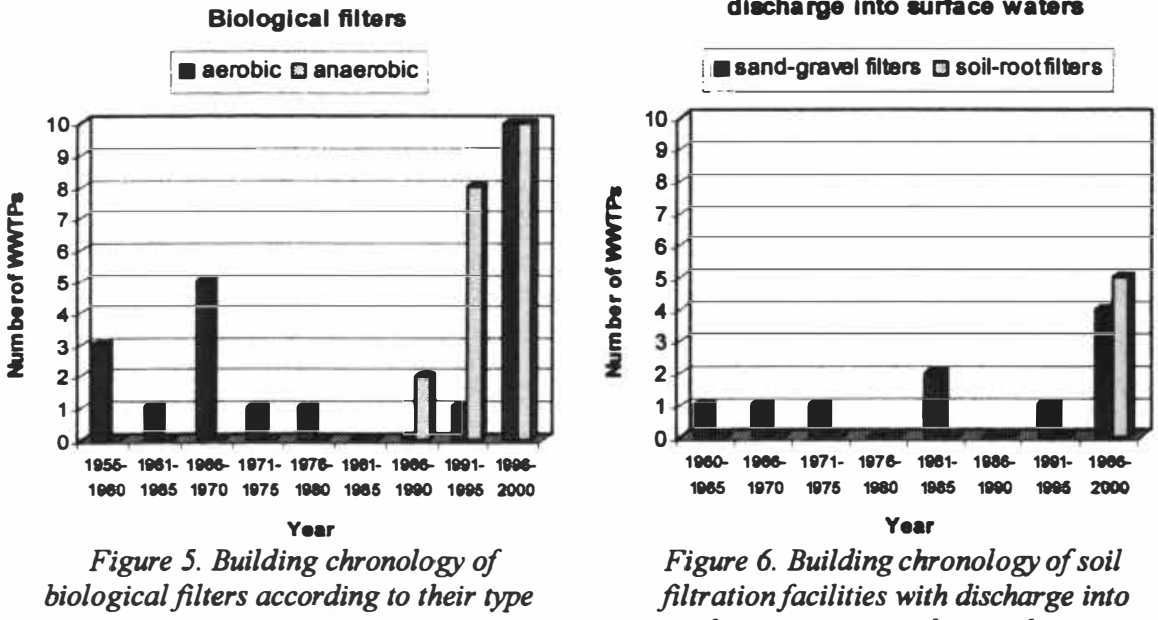

Figure 6. Building chronology of soil filtration facilities with discharge into surface waters according to their type 
Until the end of eight-decade only the aerobic biofilters were built in small settlements and rural areas of Lithuania (Figure 5). In the next decade the biofilters of such type were refused. In 1986-1995 the construction of anaerobic biofilters (submerged) was started. During this period 10 anaerobic biofilters and only one aerobic biofilter were built. It may be stated that the revival of aerobic biofilters started from 1996. During the five-year period 10 aerobic and 10 anaerobic biofilters were built. So, in the future the number of biofilters should increase and comprise more than $7 \%$ of total number of the WWTPs (Figure 3).

Two types of soil filtration facilities with discharge into surface waters are excluded. This is sand-gravel filters and soil-root filters. The latter filters were started to exploit only from 1996 (Figure 6). The first soil-root filters were constructed based on the experience of Scandinavian countries. A part of sand-gravel filters was built earlier, but more widely they are also started to exploit from 1996. So, the number of soil filtration facilities with discharge into surface waters has the trend to increase.

A lot of biological treatment technologies come from foreign countries, some technologies are also proposed by Lithuanian specialists. It may be various solutions of biological wastewater treatment that give the similar result. But their implementation cost may differ several times. The increasing number of biofilters and soil filtration facilities with discharge shows that the systems of biological fixed film and soil filtration seem to be more expedient for the WWTPs with low capacity than the activated sludge systems. However, before the biological treatment technology will be selected the diffierent possibilities should be evaluated taking into account the peculiarity of territory, development of water supply and sewerage systems, capitalmaintenance costs, maintenance possibilities, environmental requirements.

\section{CONCLUSIONS}

1. In small settlements and rural areas of Lithuania the biological treatment is the most commonly used wastewater treatment method. As the main treatment step it was applied in the $95 \%$ of the WWTPs with capacity up to $1000 \mathrm{~m}^{3} / \mathrm{d}$ in 2000 . In $68.7 \%$ of these WWTPs the activated sludge facilities are applied.

2. In 2000 the total capacity of WWTPs that have the biological treatment step very differed from the total loading. The employment of these facilities was $26 \%$. Therefore the biological treatment facilities that are applied in small settlements and rural areas of Lithuania should be orientated to the capacity up to $150 \mathrm{~m}^{3} / \mathrm{d}$.

3. In small settlements and rural areas of Lithuania the small (decentralised), cheap and easily maintained WWTPs should be applied more widely. In this respect the systems of biological fixed film and soil filtration has more advantages than the activated sludge systems. That shows the increased building of biofilters and soil filtration facilities with discharge.

4. The suitability of the biological treatment technologies should be discussed complexly taking into account the following aspects: peculiarity of territory (territorial planning), development of water supply and sewerage systems, capital and maintenance costs, maintenance possibilities, environmental requirements.

\section{ACKNOWLEDGEMENTS}

I would like to thank Dr. Patricija Didziapetriene for the valuable advises and helping to classify the types of wastewater treatment facilities for small settlements of Lithuania.

\section{REFERENCES}

1. Review Information on the State of Wastewater Treatment Plants in Lithuania (1998). Ministry of Environment, Water Department, Vilnius.

2. Summaries of statistical system "Water" (2000). Ministry of Environment of Lithuania, Joint Research Centre, Vilnius. 